\title{
A AVALIAĈ̃O DO PROGRAMA DE PÓS-GRADUAÇÃOO EM EDUCAÇÃO DA PUCPR: UMA INTERPRETAÇÃO NECESSÁRIA
}

\author{
Lilian Anna Wachowicz * \\ Maria Amélia Sabbag Zainko *
}

As instituições ligadas à educação escolar têm a capacidade de certificação, ou seja, uma atribuição regimental de qualificar ou desqualificar cursos, programas, alunos e professores, capacidade essa que, por sua vez, desencadeia toda uma "dinâmica interna de ritos de avaliação reiterados que acabam desembocando em uma qualificação final" (ANDRÉ, 1996). A avaliação com certificação está entre as funções sociais que a educação cumpre, em uma sociedade na qual o nível de escolaridade alcançado, ou o grau de rendimento que se obtém nos estudos cursados, têm a ver em grande parte com os mecanismos e oportunidades de entrada no mercado de trabalho (SACRISTÁN, 1998, p. 324 ).

Essa prática acompanha a existência da própria instituição da educação escolar na sociedade, de tal forma que já se apresenta como histórica. Assim, os estudos sobre a avaliação nos revelam que a idéia de excelência tem norteado os procedimentos técnicos, bem como as normas e os critérios de julgamento de valor, gerando algumas práticas que se incorporaram ao cotidiano das instituições, tais como a comparação entre os sujeitos avaliados, sejam eles alunos, professores, cursos ou programas, assim como a comparação dos sujeitos com critérios de competência.

Perrenoud, um dos autores que se têm ocupado do assunto, apresenta a idéia de "fabricação" da excelência escolar para evidenciar que os

* Professoras/Pesquisadoras do Programa de Pós-Graduação em Educação da PUCPR 
juízos e as hierarquias, como todas as representações, são o resultado de uma construção intelectual, cultural e social. O autor justifica ainda o uso do termo "fabricação", como uma metáfora para chamar a atenção ao poder que têm as organizações de construir uma representação da realidade e impô-la a seus membros, como se fosse a única definição da realidade (PERRENOUD, 1999). O importante a destacar aqui é que essas normas e critérios são fruto de uma construção social, mas são difundidos como se fossem a única forma possível de conceber a realidade. E a partir deles são tomadas decisões e definições que afetam o destino social dos indivíduos. (ANDRÉ, 1996 ).

Sendo tão significativa a repercussão social da avaliação, talvez seja importante explicitar o conceito de representação, especialmente o de representações sociais. Uma das autoras clássicas sobre o assunto, Mary Jane Spink, define representações sociais como sendo formas de conhecimento. Apoiando-se em Jodelet, aborda dois campos de debate que envolvem o tema das representações:

No primeiro debate, as representações emergem como uma modalidade de conhecimento prático orientado para a compreensão do mundo e para a comunicação; no segundo debate, emergem como construções com caráter expressivo, elaboração de sujeitos sociais sobre objetos socialmente valorizados.

As representações sociais, enquanto formas de conhecimento, são estruturas cognitivo-afetivas e, desta monta, não podem ser reduzidas apenas ao seu conteúdo cognitivo. Precisam ser entendidas, assim, a partir de sua funcionalidade nas interações sociais do cotidiano...As representações sociais, sendo formas de conhecimento, inserem-se mais especificamente entre as correntes que estudam o conhecimento do senso comum.

$\mathrm{O}$ segundo debate remete necessariamente à atividade do sujeito na elaboração das representações sociais . Mas, de um sujeito social...É neste sentido que afirmamos que as representações são campos sociais estruturados... Entretanto, são também uma expressão da realidade intra-individual; uma exteriorização do afeto. (SPINK, in GUARESCHI e JOVCHELOVITCH , 95, p.119-120).

A complexidade da avaliação se expressa nessas referências. A idéia é a seguinte: se a avaliação é referenciada a critérios ou padrões de excelência e se tais critérios são representações, pode haver construções sociais em torno da idéia de excelência, que são fruto do senso comum, com interferência de estruturas cognitivo-afetivas dos sujeitos envolvidos. Ou seja: podemos ter resultados de avaliação que na realidade são pré-determinados por nossas idiossincrasias e, se não nos detivermos a analisar detalhadamente, processu- 
almente e continuamente nossos julgamentos, com a crítica necessária, arriscamo-nos a emitir pareceres que não resistem ao nível de conhecimento científico, permanecendo ao nível do preconceito e do senso comum.

Por isso, o resgate da história da avaliação da pós-graduação no Brasil é necessário para o entendimento dos elementos do modelo presente hoje no processo. Segundo relatório apresentado por uma comissão que analisou a sistemática de avaliação da CAPES , as dificuldades encontradas são as seguintes: a hierarquização dos programas e cursos de pós-graduação; o caráter predominantemente quantitativo dos indicadores utilizados; a repercussão negativa da classificação, no âmbito interno e externo dos programas; a inflexibilidade dos indicadores, não levando em conta circunstâncias importantes para a compreensão da realidade desses programas; o caráter a-histórico do tipo de avaliação empregado; a influência sobre os programas, no sentido de produzir, exclusivamente, os efeitos valorizados pela sistemática utilizada; a eventual estagnação dos programas, em virtude de sua classificação formal em determinado e indelével nível; a carga negativa sobre os cursos considerados fracos e o desestímulo dos cursos considerados fortes; a própria estigmatização, por vezes estabelecida, a partir da atribuição errônea de características que não correspondem à realidade dos programas; a não valorização da autoavaliação e a supervalorização da avaliação externa, a partir dos produtos (SAUL e ABRAMOWICZ, 97, p.115).

A comissão trabalhou, apoiada e facilitada pela própria CAPES, sobre os documentos arquivados na " Memória da Pós-Graduação", em Brasília, buscando estabelecer as relações entre os relatónios apresentados pelos programas e os pareceres avaliativos enviados aos cursos, elaborados pelos comitês avaliadores ( p. 114).

A proposta elaborada em 1987 contemplava as dimensões qualitativa e quantitativa da avaliação, compreendendo: a auto-avaliação do programa; a avaliação interpares; a avaliação interprogramas e a avaliação pela comissão de consultores. Não chegou sequer a ser testada, pois não há uma resposta plausível à questão que salta aos olhos de quem estiver participando desse processo: "Para que deve servir a avaliação da pós-graduação?"

Nossa resposta, acompanhando àquela comissão é a que entende a avaliação como

Um processo crítico, associado a uma vontade política de transformação da universidade necessária a uma sociedade democrática, justa e moderna; um processo democrático, em que seja garantida a participação dos agentes da pós-graduação na construção/reconstrução de sua própria história e ao qual 
seja assegurado o acesso das várias instâncias implicadas no próprio exercício da avaliação; e uma proposta pedagógica, formativa dos agentes que atuam nos programas em oposição a uma postura classificatória dos mesmos (SAUL e ABRAMOWICZ, 97, p.117).

Tendo por base essa compreensão teórica e considerando a análise efetuada no item auto-avaliação, constante tanto do documento consolidado que serviu de base para a análise realizada pela comissão (informações fornecidas e registradas no relatório da reunião do EDUFORUM, 9 /10 de dezembro) quanto do relatório descritivo encaminhado a CAPES e ao representante da área da Educação, reforçamos a crença de que "na realidade atual, a avaliação institucional de programas, cursos ou processos de formação, coloca-se como elemento fundamental da tomada de decisões e da mudança que, muitas vezes se faz necessária".

Neste sentido e buscando desenvolver este papel se inserem e ganham relevância no interior do nosso programa as ações avaliativas, numa perspectiva de auto-avaliação, ou de um retrato do processo de formação de professores/pesquisadores, em permanente busca de aperfeiçoamento.

Como fundamentos da avaliação que pretendemos mobilizadora e estimuladora da mudança, algumas características essenciais orientam nossa prática:

- o seu caráter de globalidade (envolve não só o Programa, o curso, mas o curso no contexto da instituição);

- a construção de um processo participativo e negociado (a difícil, mas necessária busca da participação coletiva de professores, dirigentes e alunos);

- a sua função operatória e estruturante (avaliação orientada para a tomada de decisões e a transformação da realidade, ao longo do processo);

- a sua função formativa;

- a legitimidade política e técnica do processo;

- a sua capacidade de estar adaptada à instituição.

Respeitadas estas características, fica evidente que cada processo construído cotidiana e coletivamente é único, muito embora a análise de conjunto seja fundamental para compreender a trajetória de cada Programa.

No Programa de Pós-Graduação em Educação da PUCPR, várias têm sido as maneiras de construir um processo peculiar. Talvez as dificuldades encontradas ao longo do processo de credenciamento sejam hoje as principais estimuladoras desta incessante busca de qualidade acadêmico- científica.

A avaliação interna desenvolve-se por meio de discussões, de análises e também, de modo mais formal, por meio de pesquisa desenvolvida pela 
professora e os alunos da disciplina de Avaliação das Instituições de Ensino Superior.

Os resultados parciais orientam a prática e apontam para as mudanças. (p.234 - Relatório Descritivo, Julho 1999).

Este nosso exercício de auto-avaliação nos convoca e a todos os avaliadores externos a avaliar os avanços e os recuos do Curso de Mestrado em Educação, no contexto do Programa de Pós - Graduação tendo como perspectiva o compromisso do "olhar histórico", isto é compreender o presente à luz da sua trajetória.

Não parece ter sido essa a perspectiva adotada pelos responsáveis pela elaboração da Ficha de Recomendação que, analisada de forma meticulosa, apresenta uma série de contradições ditadas principalmente pela confusão estabelecida entre a idéia de curso novo e não novo.

Para melhor explicitar os aparentes equívocos é de fundamental importância que caminhemos com a análise, considerando cada um dos quesitos avaliados.

Senão vejamos:

O quesito I Proposta do Programa, contendo 4 itens, é considerado na sua totalidade adequado, merecendo na sua apreciação considerações sobre a bem articulada relação entre estrutura curricular, linhas de pesquisa, atividades docentes e infra-estrutura físico-financeira.

O quesito II Corpo Docente, composto também e como todos os demais por 4 itens, tem a sua avaliação dividida entre dois conceitos Muito Bom e Bom, sendo que a tendência relevante indicada pela Comissão é de conceito Bom.

Neste quesito evidencia-se um dos problemas de avaliação, primeiro porque não há, senão subjetivamente, indicações para que a tendência dominante seja bom, uma vez que os pesos para Muito Bom somam 60,0 e para Bom 40,0; segundo porque há incoerência de interpretação entre a avaliação quantitativa do quesito e a apreciação qualitativa a seguir, que destaca a atuação dos doutores NRD6 atribuindo-lhe a condição de bem equilibrada e distribuída. Cabe ressaltar que o item 3 atribui conceito bom exatamente a um dos pontos fortes do Programa qual seja a Titulação (somente doutores e pósdoutores), com significativa Experiência na vida acadêmica, seja na condição de professores, de pesquisadores e de administradores universitários (Diretores de Centros, Coordenadores de Programas de Pós- Graduação, Pró- Reitores de Graduação, de Pesquisa e Pós- Graduação, Vice Reitores, Reitores), consultores nacionais e internacionais em suas respectivas áreas de especialização, membros de Comitês Científicos de instituições de pesquisa, membros de Conselhos Editoriais de Revistas Especializadas, o que evidencia também 0 intercâmbio entre instituições, reforçado pela participação externa de doutores em todas as bancas de qualificação e de defesa de dissertações. Por outro 
lado , os docentes do Programa participam de projetos integrados financiados pelo CNPq,Ministério da Saúde e Organização Panamericana de Saúde envolvendo parcerias com as universidades Federais do Rio Grande do Sul, de Santa Catarina, do Paraná, de Viçosa, com as universidades particulares PUCRS, Universidade Regional de Blumenau, CEFET-PR, SIEMENS,etc.

O quesito III Atividades de Pesquisa, Desenvolvimento e Extensão, atribui ao item 3 - Participação de discentes nos Projetos de Pesquisa, Desenvolvimento e Extensão, o conceito Fraco o que sugere no mínimo uma análise aligeirada da questão, uma vez que há com financiamento do CNPq bolsistas de iniciação científica em pelo menos 5 projetos, além da participação de alunos do Mestrado em praticamente todos os projetos em desenvolvimento. Este conceito associado ao do item 4 considerado Deficiente acaba por rebaixar a tendência dominante no quesito para regular. Aqui também cabe ressaltar que nos 29 projetos relacionados entre os concluídos, em fase de conclusão e em fase inicial, 11 têm algum tipo de financiamento externo, seja por organismos nacionais: CNPq, IPEA, Ministério da Saúde, SEED, seja por organismos internacionais: Organização Universitária Internacional, Organização Panamericana de Saúde. Há, ainda, 6 projetos em fase de análise técnica por parte da Fundação Araucária, a fundação de pesquisas do Estado do Paraná, cujos recursos não foram liberados por um problema de caixa do governo estadual. Há, também, os projetos com auxílio financeiro interno que são avaliados por comissão multidisciplinar, no âmbito da Pró-Reitoria de Pesquisa e Pós- Graduação, principalmente os que se destinam a concessão de bolsas para iniciação científica. O requisito, portanto, de avaliação externa para a concessão do financiamento encontra-se plenamente atendido, assim como não pode ser considerado deficiente um programa que tem mais de $50 \%$ de seus projetos financiados por diferentes agências de fomento. Será que a não consideração dos financiamentos existentes prende-se a uma visão equivocada de que só os órgãos oficiais de pesquisa, que dispõem de muito poucos recursos, podem e devem ser considerados como agências financiadoras? Não podemos imaginar que essa seja a verdade. Por outro lado, a apreciação crítica faz menção a elevado número de projetos por professor, que necessita ser avaliado, a partir da compreensão do grau de envolvimento do professor na pesquisa. O Relatório considerou todas as formas de participação dos docentes e, portanto, graus diferentes de comprometimento e de tempo destinado, desde a imersão total até consultoria para aspectos singulares dos processos de produção do conhecimento. Os projetos concluídos não só possuem relatórios de conclusão, como muitos deles já foram objeto de publicação, inclusive de livros.

O quesito IV Atividades de Formação, possui um atributo para o item 3 - Adequação e abrangência da Estrutura Curricular relativamente à qualificação e dimensão do Corpo Docente. Participação do NRD e de outros do- 
centes, com avaliação regular, contradizendo as apreciações anteriores, que consideraram bem equilibrada e adequada a abrangência da estrutura curricular, bem como a dimensão e qualificação do corpo docente. Aqui é importante ressaltar que dos 18 professores do programa, 17 NRD6 há uma significativa participação dos docentes nas atividades da Graduação, porque entende a Universidade que essa é uma forma das mais adequadas de garantir a excelência acadêmica na instituição. Essa busca permanente da qualidade se traduz no desenvolvimento de processos de formação com características de interação e interdisciplinaridade. E por estar em permanente busca é que não nos cabe a observação de que as disciplinas possuem bibliografia insuficiente e desatualizada. Um exame mais acurado vai nos indicar que as disciplinas são atualizadas anualmente, assim como grande parte da bibliografia básica (a única listada, por exigência do instrumento, mas não a única utilizada) referese a obras da década de 90, até com publicações de 1999, excetuando-se em todas elas, aquelas consideradas clássicas, que não podem ser avaliadas pelo ano de publicação, mas pela contribuição que apresentam para o desenvolvimento da área. Dessa maneira o juízo de valor emitido, além de carecer de base de fundamentação, ainda desmerece um dos cuidados do programa e da instituição com seus processos de renovação pedagógica, que são alimentados pela participação maciça em eventos educacionais e na manutenção de um acervo em permanente atualização.

$\mathrm{O}$ quesito $\mathrm{V}$ Corpo Discente prima por enfatizar o número de desistências, considerado alto, o que não corresponde necessariamente à verdade, uma vez que nas informações complementares encontra-se devidamente explicado que dos 301 ingressantes houve uma desistência de 35 mestrandos, cerca de $12 \%$ do total, o que é bastante razoável se considerarmos a história do curso e a inexistência até hoje de bolsas para os mestrandos. Este também um dos elementos para a determinação do tempo de conclusão do curso, que vem sendo abreviado e que nos últimos anos encontra-se entre 24 e 33 meses. Em condições normais, com bolsas, os mestrandos dedicando-se integralmente ao curso, teríamos condições de fixar o tempo de conclusão em torno de 24 meses. Cabe, ainda, salientar que a avaliação do item 4 - Número de discentes-autores da pós-graduação em relação à dimensão do corpo discente; participação de discentes-autores da graduação considerado fraco, indica uma visão aligeirada dos dados uma vez que essa produção, não só existe como vem sendo incrementada a cada ano, seja pela participação dos discentes nos projetos de pesquisas dos docentes, seja pela participação maciça em encontros e seminários nacionais e regionais,seja pela oportunidade da produção conjunta que a ambiência acadêmico-científica construída no Programa abre como perspectiva para docentes e discentes.

O quesito VI Trabalhos de Conclusão expressa de forma inequívoca a confusão presente no processo de avaliação do documento, quando em seu 
item 1 - avalia como não aplicável o Vínculo das teses, dissertações e outros trabalhos de conclusão com as Áreas de Concentração, Linhas de Pesquisa e Projetos, adequação ao nível dos Cursos. Este assunto encontra-se bastante bem explicado nas informações complementares do Relatório encaminhado. O vínculo existe sim, porque o programa não é novo e não só possui teses concluídas e defendidas,como também em fase de elaboração. Por outro lado, o item 2 - Tempo médio de titulação de bolsista e não bolsista; tempo médio de bolsa, considerado como fraco não existe porque o programa inexiste para as agências financiadoras. O item 3 - Número de titulados em relação à dimensão do NRD, participação de outros docentes na orientação dos titulados por sua vez, considerado regular, contraria a apreciação de adequação e equilíbrio na dimensão do corpo docente NRD6, em relação ao corpo discente. Por último, neste quesito a qualificação das Bancas examinadoras, analisada sob o olhar histórico, desconsidera o enorme esforço dos últimos anos na composição de bancas exclusivamente de doutores e com participação externa em todas elas, sejam de qualificação ou de defesa. A avaliação regular, além de injusta é equivocada, pois não corresponde à realidade.

O quesito VII Produção Intelectual apresenta dificuldades para 0 entendimento do juízo de valor da comissão, não só pela contradição existente entre a atribuição de conceitos e a apreciação qualitativa, como também pela inversão dos valores em relação à produção apresentada. No item 2 Relevância da produção intelectual e qualidade dos seus veículos ou meios de divulgação avaliado como fraco, a relevância da produção intelectual está associada à qualidade dos meios de divulgação, com visível predominância destes. Ora, o que é uma produção marcadamente regional? Isto é ruim ? O Programa não deve contribuir para a formação de intelectuais e para a produção da ciência, seja ela regional ou nacional? Publicar livros nas Editoras Cortez Autores Associados, Papirus, Vozes, localizadas no eixo Rio/São Paulo é publicar só para a região? O que importa, realmente, o nome da Editora, ou o seu eficiente sistema de distribuição, que coloca o conhecimento produzido acessível aos profissionais da área no País e no Exterior? Uma Editora Internacional, representando um conjunto de universidades, que coloca em parceria com uma editora local o conhecimento produzido à disposição de latinoamericanos, europeus, americanos do norte, é menos importante que uma editora do eixo considerado? O mesmo raciocínio vale para a publicação de periódicos em revistas da UNICAMP, da Federal de São Carlos, da Federal do Rio Grande do Norte, da Federal de Pernambuco, da UNIMEP, da UNESP, da Veiga de Almeida, da Estadual de Maringá, da PUC do Rio Grande do Sul, da Federal de Santa Catarina, da Federal de Minas Gerais, de Juiz de Fora, do CRUB, da ABM, do INEP, para citar apenas algumas das publicações de nossos docentes. Isto é local, ou marcadamente regional? E as publicações em revistas estrangeiras como a Educación Superior y Sociedad da UNESCO, a do 
Instituto de Liderança e Gestão Universitária - IGLU, a Série Evaluaciones Externas da CONEAU/Argentina, os Cuadernos de Planeamiento y Evaluación da Universidad Del Litoral-Argentina, as publicações em "journal" americanos e canadenses? Impossível imaginar que os avaliadores não estejam familiarizados com a gama variada de publicações que levam nossas idéias, nossas produções e nossas perspectivas de intercâmbio além fronteiras, isto sem falar nas inúmeras possibilidades criadas pela internet. Finalmente, cabe salientar que os jornais locais (Gazeta do Povo, Folha de Paraná, O Estado do Paraná), a Folha de São Paulo, A Gazeta Mercantil, O Estado de São Paulo, não podem ser considerados como meios de divulgação fracos, porquanto atingem todo o território nacional e por meio eletrônico ganham o mundo. É preciso que os avaliadores da área da Educação estejam sintonizados com a Educação do Futuro. A observação relativa aos resumos do encontro de pesquisadores da Região Sul não é procedente, uma vez que os Programas enviaram para a Coordenação do Encontro não só os resumos, mas também os trabalhos completos, que ainda não foram publicados por insuficiência de recursos financeiros. A produção intelectual não pode também ser a responsável pelos equívocos administrativos da organização dos eventos. O compromisso assumido com os coordenadores era o de uma publicação dos anais contendo os trabalhos no mês de Outubro.

Com essas considerações e com a constatação "in loco" de que este é efetivamente um Programa em fase de aperfeiçoamento, de respeito às orientações emanadas dos órgãos superiores, de avaliação contínua e sistemática, entendemos que a avaliação realizada possa e deva também ser aperfeiçoada e com isso cumprir o seu fundamental papel que é o de ser instrumento de diagnóstico e de orientação da tomada de decisões rumo à excelência dos Programas - objetivo síntese, por todos almejados.

\section{Referências Bibliográficas}

ANDRÉ, Marli E. D. A. Avaliação escolar: além da meritocracia e do fracasso. Cadernos de Pesquisa, n. o 99, nov. São Paulo : 1996.

DIAS SOBRINHO, José. A educação superior e a construção do futuro. InformAndes. Andes - SN. Ano IX, n. 84, Agosto 1999.

PERRENOUD, Philippe. Avaliação: da excelência à regulação das aprendizagens. Entre duas lógicas. Porto Alegre: Artes Médicas Sul, 1999.

SACRISTÁN, J. Gimeno e PÉREZ GOMEZ, A, I. Compreender e tranformar o ensino. Porto Alegre : Artes Médicas, 1998. 
SAUL, Ana Maria e ABRAMOWICZ, Mere. Avaliação da pós-graduação: superamos os limites? Educação Brasileira. Revista CRUB, 19 (38), p. 111-119, 1.으. 1997.

SPINK, Mary Jane. Desvendando as teorias implícitas: uma metodologia de análise das representações sociais. Textos em representações sociais. GUARESCHI, Pedrinho e JOV CHELOVITCH, Sandra (org.). 3 ed. Petrópolis : Vozes, 1997. 